\title{
New editor statement
}

\author{
Toddi A. Steelman
}

Published online: 24 January 2009

(C) Springer Science+Business Media, LLC. 2009

As the new Editor-in-Chief of Policy Sciences, I want to take this opportunity to articulate the purpose of the journal and how it fits into the broader intellectual landscape. The policy sciences are distinctive within the policy movement in that they embrace the scholarly traditions innovated and elaborated by Harold D. Lasswell and Myres S. McDougal. Within these pages we provide space for approaches that are problem-oriented, contextual, and multi-method in orientation. There are many other journals in which authors can take top-down, deductive, and large-sample approach or adopt a primarily theoretical focus. Policy Sciences encourages systematic and empirical investigations in which problems are clearly identified from a practical and theoretical perspective, are well situated in the extant literature, and are investigated utilizing methodologies compatible with contextual, as opposed to reductionist, understandings. We tend not to publish pieces that are solely theoretical, but favor works in which the applied policy lessons are clearly articulated.

Policy Sciences favors, but does not publish exclusively, works that either explicitly or implicitly utilize the policy sciences framework. The policy sciences can be applied to articles with greater or lesser intensity to accommodate the focus of an author's work. At the minimum, this means taking a problem oriented, multi-method or contextual approach. At the fullest expression, it may mean leveraging central theory or explicitly applying aspects of the framework, which is comprised of three principal dimensions: (1) social process, which is mapped in terms of participants, perspectives, situations, base values, strategies, outcomes and effects, with values (power, wealth, enlightenment, skill, rectitude, respect, well-being, and affection) being the key elements in understanding participants' behaviors and interactions; (2) decision process, which is mapped in terms of seven functions-intelligence, promotion, prescription, invocation, application, termination, and appraisal; and (3) problem orientation, which comprises the intellectual tasks of clarifying goals, describing trends, analyzing conditions, projecting developments, and inventing, evaluating, and selecting alternatives. There is a more extensive core literature that also applies and can be visited at the policy sciences website: http://www. policysciences.org/classicworks.cfm.

T. A. Steelman $(\bowtie)$

Raleigh, NC, USA

e-mail: tasteelm@ncsu.edu 
In addition to articles that explicitly utilize the policy sciences framework, Policy Sciences has a long tradition of publishing papers that draw on various aspects of that framework and its central theory as well as high quality conceptual pieces that address key challenges, opportunities, or approaches in ways congruent with the perspective that this journal strives to maintain and extend.

I look forward to my tenure over the next 3 years and welcome any queries on behalf of authors to clarify how appropriate work might best fit with our pages.

Sincerely,

Toddi A. Steelman, Ph.D.

Editor in Chief

Policy Sciences 